\title{
Author Index Volume 27 (2007)
}

The issue number is given in front of the page numbers.

Amin, M., Article repositories and journal subscription - future scenarios

(4) $173-177$

Anagnostopoulos, I. and I. Maglogiannis, Monitoring browsing behaviour and search services evolution adaptation with a capture-recapture Internet-based programming technique: A case-study over medical portals

Anderson, N., see Hodge, G.

(3) $105-122$

$(1,2) \quad 45-63$

Baer, J.-M., Academic publishing in Europe: Looking ahead

Ball, R. and J. Goebelbecker, NUCLiB - The virtual nuclear engineering library on the Internet Brown, D. and B. Dumouchel, Understanding user behaviour and its metrics

Brünger-Weilandt, S., E-Science - Advancing new ways of scientific communication

(4) 239-244

$(1,2) \quad 35-43$

$(1,2) \quad 3-34$

(4) $161-166$

Cave, F., see Green, B.

Cockerill, M., Pricing, business models and open access: Status quo vs. Apocalypse

Coker, G., Usability in emerging e-content environments

(4) $215-219$

(4) $235-238$

(4) $179-184$

Costopoulou, C., see Karetsos, S.

(3) $123-132$

Dumouchel, B., see Brown, D.

$(1,2) \quad 3-34$

Ekkel, T. and J. Kaizer, AquaBrowser: Search and information discovery for libraries

Forster, H., The i2010 digital libraries initiative: Europe's cultural and scientific information at the click of a mouse

(4) $155-159$

Goebelbecker, J., see Ball, R.

Green, B., D. Martin and F. Cave, ONIX for licensing terms: Standards for the electronic communication of usage terms

$(1,2) \quad 35-43$

(4) $215-219$

Hodge, G. and N. Anderson, Formats for digital preservation: A review of alternatives and issues

$(1,2) \quad 45-63$

$(1,2) \quad 79-83$

Kaizer, J., see Ekkel, T.

Karetsos, S., C. Costopoulou, A. Sideridis, C. Patrikakis and M. Koukouli, Bio@gro An online multilingual organic agriculture e-services platform

(3) $123-132$

(4) $167-171$

Kempe, J., BookStore - Strategic options of a publisher-driven service

(3) $123-132$

Koukouli, M., see Karetsos, S.

Kulathuramaiyer, N., see Maurer, H.

Küster, A., APE 2007: Pre-conference day - "Embracing Change" Scenario: "The European Journal for Nuclear Sinus Treatments". Journal Marketing Workshop

(4) 185-191

(4) $153-154$

Lor, P.J., Libraries in times of open access.

(4) 193-205 
Maglogiannis, I., see Anagnostopoulos, I.

(3) $105-122$

Martin, D., see Green, B.

Maurer, H. and N. Kulathuramaiyer, Addressing plagiarism and IPR violation

(4) $215-219$

Meckes, R., Pricing in Academic Publishing: A wake-up call to the online era

Meinecke, I., APE 2007: Pre-conference day - "Embracing Change" Workshop: University presses and open access

(4) $185-191$

(4) $221-228$

Patrikakis, C., see Karetsos, S.

Pedersen, C.V., Who are the oracles - Is Web 2.0 the fulfilment of our dreams?

Pesch, O., Usage statistics: About COUNTER and SUSHI

(4) $147-152$

(3) $123-132$

(3) $87-90$

(4) $207-213$

Sideridis, A., see Karetsos, $\mathrm{S}$.

(3) $123-132$

Snyder, T., Pricing and pricing policies from the perspective of a subscription agent

(4) 229-233

Stock, W.G., Folksonomies and science communication. A mash-up of professional science databases and Web 2.0 services

Svensson, L.G., National Web Library 2.0: Are national libraries ready for the new version?

(3) $97-103$

(3) $91-95$

van Halm, J., Strategic action agenda for preservation in research libraries

$(1,2) \quad 65-78$

Winters, K.-P., Welcome

(4) $145-146$ 